* Doutor em Direito em 2008 pela Universidade Católica de São Paulo (PUC/PR).

Mestre em Direito em 2001 pela Universidade de Franca (UNIFRAN).

Especialista em Direito em 2000 pela Universidade de Franca (UNIFRAN).

Graduada em Direito em 1985 pela Faculdade Metropolitanas Unidas (FMU).

E-mail: nfinotti1@gmail.com

** Mestrando em Direito pelo Centro Universitário Eurípedes de Marília (UNIVEM)

Especialista em Direito

Notarial e Registral em 2017 pela Universidade Anhanguera (UNIDERP).

Especialista em Direito

Processual do Trabalho em 2016 pela Universidade Anhanguera (UNIDERP).

Graduada em Direito em 2003

pelo Centro Universitário

Eurípede de Marília (UNIVEM)

E-mail: renan.kirihata@gmail. com

\section{A Ata Notarial}

\section{NotARial TESTIMONY}

\section{Nelson Finotti Silva*} Renan Kirihata**

Como Citar: SILVA, Nelson Finotti; KIRIHATA, Renan. Ata Notarial. Scientia Iuris, Londrina, v. 23, n. 1, p. 10-24, mar. 2019. DOI: $10.5433 / 2178-8189.2019 v 23 n 1 p 10$. ISSN: 2178-8189.

Resumo: Este trabalho traz uma revisão bibliográfica e reflexões acerca da ata notarial, instrumento público lavrado pelo tabelião de notas, analisando-se o conceito e a estrutura desse meio de prova, a sua contribuição para o acesso à justiça, bem como a classificação das atas segundo a doutrina, com destaque para quatro tipos de atas notariais em espécie: ata de mera percepção; ata de notoriedade; ata de subsanação; e carta de sentença notarial.

Palavras-chave: Ata notarial. Serventias extrajudiciais.

Processo civil. Prova civil.

Abstract: This paper presents a bibliographical review and reflections on the notarial testimony, a public instrument drafted by the notary of notes, analyzing the concept and structure of this evidence, its contribution to the access to justice, as well as the classification of the minutes according to the doctrine, with emphasis on four types of notarial acts in kind: minutes of mere perception; records of notoriety; rectification minutes; and letter of sentence.

Keywords: Notary testimony. Extrajudicial service. Civil procedure. Civil proof. 


\section{INTRODUÇÃO}

O presente artigo pretende discorrer acerca da ata notarial, instrumento público lavrado pelo tabelião de notas, analisando o conceito e a estrutura desse meio de prova, a sua contribuição para o acesso à justiça, bem como a classificação das atas segundo a doutrina, com destaque para quatro tipos de atas notariais em espécie: ata de mera percepção; ata de notoriedade; ata de subsanação; e carta de sentença notarial. Para isso, foi realizada uma revisão bibliográfica do tema com foco em doutrinadores atuais, códigos de normas e o CPC/15.

A ata notarial foi prevista como meio típico de prova pelo CPC/15 (apesar de já prevista pelo ordenamento jurídico na Lei 8.935/94), sendo salutar a alteração para a divulgação e disseminação dessa importante ferramenta jurídica que, apesar de muito útil, ainda é pouco utilizada.

A ata notarial, em sua essência, tem a mesma natureza da prova testemunhal. De fato, o tabelião testemunha os fatos e os relata na ata notarial. A diferença é que o Estado outorgou a fé pública a esse profissional do direito, que faz do documento notarial um documento público qualificado pela fé pública. A fé pública do tabelião permite que ele autentique fatos, dotando a ata notarial de uma especial eficácia e valor probante. Para isso, o tabelião de notas tem uma função autenticadora intrínseca para poder desempenhar a sua atividade.

\section{BREVÍSSIMO HISTÓRICO}

Ensina Brandelli (2009, p. 317) que “[...] embora possa parecer instituto novo, em virtude de só recentemente ingressar na pauta das discussões do cenário jurídico pátrio, a ata notarial é tão antiga quanto à própria função notarial”.

A ata notarial é um meio de prova e seu objetivo precípuo é produzir provas, sendo um verdadeiro instrumento público. Foi prevista inicialmente na legislação brasileira na Lei $\mathrm{n}^{\circ} 8.935$, de 18 de novembro de 1994 no art. $6^{\circ}$, que atribuiu aos notários a competência, dentre outras, de autenticar fatos e nos termos do art. $7^{\circ}$, III, da mesma lei trata-se de ato privativo do tabelião de $\operatorname{notas}^{1}$.

Pode-se, entretanto, afirmar-se que, mesmo antes da Lei $n^{\circ} 8.935 / 94$, a confecção da ata notarial era possível, com base no art. $364^{2}$ do CPC/73. O art. $405^{3}$ do CPC/15, em redação quase idêntica, trouxe previsão semelhando ao art. 364 do CPC/73.

$\mathrm{O} \mathrm{CPC} / 15$ deu maior destaque à ata notarial ao prevê-la no art. $384^{4}$. Loureiro (2017, p. 1214) destaca que, de acordo com esse novo dispositivo, a ata notarial "é o documento apto para atestar ou documentar a existência e o modo de existir de algum fato, lavrado pelo tabelião a

1 Art. $7^{\circ}$ Aos tabeliães de notas compete com exclusividade: [...] III - lavrar atas notariais; [...].

2 Art. 364. O documento público faz prova não só da sua formação, mas também dos fatos que o escrivão, o tabelião, ou o funcionário declarar que ocorreram em sua presença.

3 Art. 405. O documento público faz prova não só da sua formação, mas também dos fatos que o escrivão, o chefe de secretaria, o tabelião ou o servidor declarar que ocorreram em sua presença.

4 Art. 384. A existência e o modo de existir de algum fato podem ser atestados ou documentados, a requerimento do interessado, mediante ata lavrada por tabelião. Parágrafo único. Dados representados por imagem ou som gravados em arquivos eletrônicos poderão constar da ata notarial. 
requerimento do interessado". Assevera ainda que, além do meio escrito, a ata pode conter registro de som e imagens, que passam a ser parte integrante do documento notarial. Aparentemente, do ponto de vista técnico, o art. 384 do $\mathrm{CPC} / 15$ soa como desnecessário, visto que existem outros dispositivos que legitimam a sua utilização.

\section{CONCEITO DA ATA NOTARIAL}

Vários autores se propuseram a definir o conceito de ata notarial que é um instrumento público, voltado à pré-constituição de prova. Assim, colaciona-se a seguir uma série de assertivas para tentar delimitar o instituto. Segundo Loureiro (2017, p. 1214):

Ata notarial é o documento que se destina à constatação de fatos ou a percepção que dos mesmos tenha o notário sempre que por sua índole não possam ser qualificados de contratos, assim como seus juízos e qualificações. Em outras palavras, é o instrumento público que tem por finalidade conferir fé pública a fatos constatados pelo notário, por meio de qualquer de seus sentidos, destinandose à produção de prova pré-constituída.

Os notários e registradores sofrem intensa regulação administrativa das corregedorias dos tribunais de justiça. Esses tribunais costumam editar provimentos ou resoluções ditando um código de normas a ser observado pelos titulares das serventias extrajudiciais. Entre esses regulamentos, o Código de Normas de Minas Gerais trouxe um conceito de ata notarial5:

Art. 234. A ata notarial, dotada de fé pública e de força de prova pré-constituída, é o instrumento em que o tabelião, seu substituto ou escrevente, a pedido de pessoa interessada, constata fielmente os fatos, as coisas, pessoas ou situações para comprovar a sua existência ou o seu estado (MINAS GERAIS, 2013).

O Código de Normas de Minas Gerais destaca a qualidade de fé pública e da força de prova pré-constituída. Por isso, utiliza a palavra instrumento ao invés da palavra documento. Daniel Amorim Assumpção Neves (2017, p. 781) diferencia documento de instrumento nos seguintes termos:

Documento não se confunde com instrumento, sendo o segundo espécie do primeiro. $\mathrm{O}$ instrumento é produzido com o objetivo de servir de prova, como ocorre na celebração de um contrato ou escritura pública. Caso o documento seja produzido, já tendo o objetivo de provar determinado ato, será considerado um instrumento, mas, não tendo tal finalidade específica, embora em momento posterior até possa vir a ser considerado como prova num processo judicial, terse-á somente um documento, e não um instrumento, como ocorre numa carta ou e-mail tendo como conteúdo algum fato ou ato.

5 Rodrigues e Ferreira (2016, p. 112) alinham-se ao entendimento do código mineiro, quando dispõem: “Ata notarial é o instrumento público pelo qual o tabelião, ou preposto autorizado, a pedido de pessoa interessada constata fielmente fatos, coisas, pessoas ou situações para comprovar a sua existência ou seu estado." 
O código mineiro destaca também o princípio da rogação. O Tabelião deve ser instado a promover a lavratura da ata notarial. Sem essa provocação, deve se manter inerte. É preciso que algum usuário o inste para que aja ${ }^{6}$. Loureiro (2017, p. 1206-1207) assevera que o requerimento deve ser prévio; que o pedido deve ser possível de ser atendido pelo notário, podendo recusar documentar situações que envolvam esforço físico excessivo ou risco físico; que o pedido deve explicitar e determinar o evento a ser constatado; que o objeto da rogação deve ser lícito, o que não se confunde com o objeto da ata notarial; que a rogação deve obedecer a um interesse legítimo do requerente, correspondente a um interesse juridicamente protegido. Por seu turno, Pedroso e Lamanauskas (2013, p. 241) entendem:

Seu conceito se resume a um instrumento público em que o tabelião translada um fato que presenciou, por meio de seus sentidos, para um documento e, consequentemente, para os livros de notas, confirmando a existência de determinadas circunstâncias. [...] Ressalte-se que, no momento em que o notário captura o fato, não deve agir com qualquer juízo de valor sobre o que viu ou ouviu. [...].

Já as Normas de Serviço da Corregedoria Geral da Justiça do Estado de São Paulo destacam que a ata deve se converter em uma narração objetiva, fiel e detalhada de fatos jurídicos presenciados ou verificados pessoalmente pelo tabelião de notas ${ }^{7}$. Assim, não cabe na ata notarial opiniões e julgamentos, mas apenas relatos de questões fáticas. Continuando, Brandelli (2009, p. 321) assevera que:

A ata notarial é, enfim, o instrumento público mediante o qual o notário capta, por seus sentidos, uma determinada situação, um determinado fato, e o traslada para seus livros de notas ou para outro documento. É a apreensão de um ato ou fato jurídico, pelo notário, e a transcrição dessa percepção em documento próprio.

Tanto as normas de serviço, como os autores referidos, destacam uma característica: narração de fatos constatados por meio de sentidos sem emissão de juízo de valor. O notário deve se limitar a captar e transcrever o que presenciou, pois a ata tem natureza autenticatória e, por isso, não está sujeita à qualific ação da regularidade dos fatos constatados, mas simplesmente à sua descrição da forma mais fiel possível.

A escritura pública e a ata notarial são documentos diferentes. A escritura pública deve atender aos requisitos do art. 215 do Código Civil, sendo que "[...] a regra não se aplica, por inteiro, à ata notarial, embora também subordinada a critérios formais, inerentes à função de quem a redige, com a correspondente avaliação de fatos cuja exatidão não possa ser presumida" (CENEVIVA, 2010, p. 85).

6 "Dado o predomínio na lei brasileira do princípio da instância, não é de acolher a ata notarial de ofício, pela qual o tabelião lança em seus livros ata de sua iniciativa." (CENEVIVA, 2010).

7 Cap. XIV. 137. Ata notarial é a narração objetiva, fiel e detalhada de fatos jurídicos presenciados ou verificados pessoalmente pelo Tabelião de Notas. 137.1 A ata notarial é documento dotado de fé pública. (ESTADO DE SÃO PAULO, 1989, p. 51.) 
A ata notarial, enquanto ato de competência privativa do tabelião de notas, foi prevista em nosso ordenamento de forma expressa no art, $7^{\circ}$, III, da Lei $n^{\circ} 8.935 / 94$, enquanto a menção à escritura pública foi prevista no inciso I. Assim, quis o legislador mostrar que se tratam de institutos diferentes. Deveras, a natureza jurídica da ata notarial é autenticatória, e a da escritura pública é constitutiva obrigacional. Assim, a ata notarial é um instrumento público, destinada à pré-constituição de prova, mediante a qual o tabelião de notas, a requerimento da parte suscitante, relata fatos percebidos de forma seletiva sem emissão de juízo de valor, dando o seu testemunho, que é recoberto pela fé pública outorgada pelo Estado.

\section{FINALIDADE DA ATA NOTARIAL}

A ata notarial tem em si a característica da reconstrução de fatos pretéritos. Os fatos não podem ser repetidos, mas o relato do fato pode ser reconstruído, e a partir de aí ser utilizado para reconstruir o fato propriamente dito. Nesse sentido, a ata notarial é um documento histórico, no sentido de descrever a história de determinado acontecimento.

O método reconstrutivo é um método composto, que combina vários processos lógicos. Parte da observação, e por isso o reconstrutor está sujeito às normas desse processo: não recolhe tudo de forma mecânica, mas antes seleciona o que considera importante (DELLEPIANE, 2004, p. 40-41).

Segundo Loureiro (2017, p. 1205), “[...] a finalidade da ata notarial é a constatação de fatos pelo notário com a finalidade de formar prova para fins administrativos ou judiciais". O solicitante da ata espera produzir uma prova de forma deliberada para evidenciar determinado fato jurídico relevante. Assim, a ata notarial, além de ser um documento público, é um verdadeiro instrumento, vez que destinada a fazer prova.

A ata notarial é um ato autenticador, já que, por meio da ata notarial, o tabelião de notas autentica fatos. Pode ser objeto da ata notarial o fato jurídico em sentido amplo, incluídos tanto os fatos lícitos quanto os ilícitos, pois ambas as espécies produzem efeito jurídico que podem fundamentar uma pretensão legítima (LOUREIRO, 2017, p. 1205-1206).

Conclui-se então que a função da ata notarial é servir de instrumento público, visto que destinada a fazer prova futura de fato constatado e narrado pelo tabelião, que possui fé pública, de forma a permitir a prevenção de conflitos ou a sua célere resolução.

\section{ESTRUTURA DA ATA NOTARIAL}

Não há previsão legal acerca dos elementos que devem ser considerados para a validade de uma ata notarial, não se aplicando integralmente o art. 215 do Código Civil às atas notariais.

Ao lavrar e materializar os conteúdos para o texto da ata notarial, o tabelião de notas não realiza controle e qualificação quanto à: manifestação da vontade das partes; necessidade de assinatura das partes, visto que a ata notarial é ato unilateral do tabelião de notas; referência 
ao cumprimento das formalidades legais e fiscais, visto que não é entabulado nenhum negócio jurídico, mas mera descrição de fatos captados por meio dos sentidos do tabelião.

Os códigos de normas dos tribunais de justiça estaduais regulam o tema, discorrendo sobre os requisitos necessários à lavratura de atas notariais. Nessa toada, o Código de Normas de Minas Gerais dispõe:

Art. 235. São requisitos de conteúdo da ata notarial: I- data e lugar de sua realização, indicando a serventia em que tenha sido lavrada; II - nome e individualização de quem a tiver solicitado; III - narração circunstanciada dos fatos; IV - declaração de ter sido lida ao solicitante e, sendo o caso, às testemunhas, ou de que todos a leram; V - assinatura do solicitante e, sendo o caso, das testemunhas, bem como do tabelião de notas, seu substituto ou escrevente, encerrando o ato (MINAS GERAIS, 2013).

Já as normas de São Paulo dispõem:

CAP XIV. 138. A ata notarial conterá: a) local, data, hora de sua lavratura e, se diversa, a hora em que os fatos foram presenciados ou verificados pelo Tabelião de Notas; b) nome e qualificação do solicitante; c) narração circunstanciada dos fatos; d) declaração de haver sido lida ao solicitante e, sendo o caso, às testemunhas; e) assinatura e sinal público do Tabelião de Notas (SÃO PAULO, 1989, p. 51).

Rodrigues e Ferreira (2016) admitem que o relativamente capaz, entre 16 e 18 anos, e os incapazes detentores de capacidade natural podem requerer a lavratura de ata notarial. Loureiro (2017, p. 1210) entende que não há exigência de que o requerente seja pessoa capaz, desde que tenha aptidão natural para entender e querer, visto que o autor do documento é o notário. Por exemplo, um pródigo, considerado relativamente incapaz pelo Código Civil ${ }^{8}$, pode solicitar a lavratura de uma ata notarial registrando um comentário ofensivo postado em uma página na internet.

O notário também está sujeito aos impedimentos constantes do art. 27 da Lei ${ }^{\circ}$ 8.935/94, ou seja, “[...] no serviço de que é titular, o notário e o registrador não poderão praticar, pessoalmente, qualquer ato de seu interesse, ou de interesse de seu cônjuge ou de parentes, na linha reta, ou na colateral, consanguíneos ou afins, até o terceiro grau” (CENEVIVA, 2010, p. 228), sendo que “[...] inexiste fé pública no ato que o notário ou registrador pratique em seu próprio benefício" (CENEVIVA, 2010, p. 228).

Também é preciso identificar e qualificar a parte, ou seja, o solicitante, e sempre que possível as outras pessoas devem ser qualificadas tendo em vista o princípio da segurança jurídica?

8 Art. $4^{\circ}$. São incapazes, relativamente a certos atos ou à maneira de os exercer: [...] IV - os pródigos.

9 "Para atas notariais, o reconhecimento da identidade e capacidade da parte e sua qualificação são imprescindíveis. Parte é somente o solicitante. A presença de outras pessoas, a pedido do solicitante, como peritos, assistentes técnicos e testemunhas, implica no dever de reconhecer a identidade e a capacidade e qualificá-las para o ato notarial. / Não é imprescindível que sejam reconhecidas as identidades e capacidades, ou requerida a qualificação, de terceiros presentes nos fatos constatados. Se, porém, o tabelião puder, deve fazer tal constatação, que amplia o elenco da autenticação e agrega maior segurança ao ato.” (RODRIGUES; FERREIRA, 2016). 
As partes não precisam assinar a ata notarial. Pode ocorrer de o solicitante não concordar com o conteúdo da ata notarial e recusar-se a assiná-la. Nesse caso, o tabelião pode lançar a sua assinatura e mencionar tal circunstância. Rodrigues e Ferreira (2016) asseveram que: "[...] as assinaturas das partes são indispensáveis para perfectibilizar as escrituras. Nas atas, se faltar a assinatura do solicitante ou quaisquer intervenientes, o notário pode finalizar o ato, que é válido e eficaz". A assinatura do solicitante na ata notarial, bem como testemunhas, implica somente em mera ciência do conteúdo da ata, e não concordância.

Em atenção ao princípio da unidade do ato, a ata deve conter o tempo e local de sua lavratura, bem como o tempo e o local dos fatos constatados pelo tabelião: “[...] o princípio da unidade do ato deve ser cumprido no momento da redação final, da lavratura e assinatura das partes e do tabelião" (RODRIGUES; FERREIRA, 2016).

Assim, apesar de não existir um dispositivo legal regulando a estrutura da ata notarial, o art. 215 do Código Civil deve servir de guia básico no que couber. Os regulamentos administrativos também dão uma diretriz sobre os pontos importantes que devem fazer parte da ata.

A doutrina, por sua vez, complementa com discussões a operacionalização da lavratura, mas a análise e o prudente arbítrio do notário é que irá dotar de plena eficácia a ata notarial: cabe ao notário, no caso concreto, identificar os elementos que serão importantes, complementando a ata dos elementos necessários.

\section{CLASSIFICAÇÃO DA ATA NOTARIAL}

Existem diversas espécies de atas notariais e no presente texto serão tomadas as obras de Brandelli, Loureiro e Rodrigues e Ferreira como referencial principal. Os nomes e as classificações adotadas pelos autores não são uniformes, e nem mesmo o conteúdo de cada tipo de ato. Todavia, há uma grande similitude nos exemplos de aplicação prática. Apesar de divergentes na nomenclatura, há uma certa sintonia de entendimentos.

A doutrina possui diversas classificações de ata notarial. Rodrigues e Ferreira (2016) classificam as atas quanto: a) ao agir do tabelião; b) ao objeto; c) à forma; e d) ao meio.

A classificação de Rodrigues e Ferreira é interessante, pois apresenta diversos critérios. Outros autores também apresentam uma taxinomia das atas, mas, geralmente, distinguindo-as em função do objeto. Por ser este ${ }^{10}$ o principal critério de classificação da doutrina, iremos nos concentrar em alguns dos tipos mais comentados de ata notarial.

Rodrigues e Ferreira (2016) classificam as atas nas seguintes espécies: ata de notoriedade;

10 O parágrafo único do art. 234 do Código de Normas de Minas Gerais dispõe que a ata notarial pode ter como objeto: "Parágrafo único. A ata notarial pode ter por objeto: I - colher declaração testemunhal para fins de prova em processo administrativo ou judicial; II - fazer constar o comparecimento, na serventia, de pessoa interessada em algo que não se tenha realizado por motivo alheio à sua vontade; III - fazer constar a ocorrência de fatos que o tabelião de notas ou seu escrevente, diligenciando em recinto interno ou externo da serventia, respeitados os limites da circunscrição nos termos do art. 146 deste Provimento, ou em meio eletrônico, tiver percebido ou esteja percebendo com seus próprios sentidos; IV - averiguar a notoriedade de um fato. $\mathrm{V}$ - atestar o tempo de posse do requerente e de seus antecessores, conforme o caso e suas circunstâncias, para fins de reconhecimento de usucapião." (MINAS GERAIS, 2013). 
ata de declaração; ata de certificação sobre documentos e exibição de coisas; ata de constatação em diligência externa; ata de notificação; ata de autenticação eletrônica; ata de usucapião; ata de subsanação. Já Brandelli (2009) cita: ata de protocolização (não prevista no direito brasileiro); ata de depósito (não prevista no direito brasileiro); atas de presença; ata de notificação (sem aplicação no direito brasileiro); ata de notoriedade; ata de subsanação. Loureiro (2017, p. 1212) lista: atas de mera percepção de coisas, de pessoas ou de condutas humanas; atas de juízo e qualificação do notário; ata de manifestação; ata de protocolização de documentos (cartas de sentença notariais).

A seguir serão estudados quatro tipos de atas notarias com mais detalhes: atas de mera percepção; atas de notoriedade; atas de subsanação; e cartas de sentença notariais.

\subsection{Atas de mera percepção}

Loureiro denomina de atas de mera percepção o registro da percepção, pelo notário, de coisas, pessoas ou de condutas humanas, asseverando que a ata de mera percepção é expressamente consagrada ${ }^{11}$ no art. $703^{12}$ do $\mathrm{CPC} / 15$.

A ata de mera percepção tem sido utilizada, por exemplo, no âmbito das relações de trabalho para constatar que determinado funcionário denigre a imagem da própria empresa em redes sociais na internet.

Rodrigues e Ferreira (2016) não utilizam tal terminologia, mas fazem remissão à ata de declaração; ata de verificação sobre documentos e exibição de $\operatorname{coisas}^{13}$; ata de constatação em diligência externa ${ }^{14}$; ata de autenticação eletrônica. Dentro das atas de autenticação eletrônica, Rodrigues e Ferreira cita a ata de internet, que seria uma subespécie:

Com o avanço da tecnologia e o crescimento da internet, há uma enorme quantidade de relações, documentos e contratos realizados por via digital. A ata notarial possibilita comprovar a integridade e veracidade de fatos em meio digital, ou atribuir a eles autenticidade. [...] É frequente que esses locais tenham informações

11 “A possibilidade deste tipo de ata é expressamente consagrada no art. 703 do Novo Código de Processo Civil. Segundo esta norma, o notário homologará o penhor legal tomado pelos proprietários de hotéis e restaurantes (consistente na apreensão de bens móveis daqueles que deixam de pagar os débitos pela prestação dos serviços concernentes). Tal fato é documentado em ata notarial, onde deve ser feita menção, ainda, ao contrato de locação ou a conta pormenorizada das despesas, a tabela dos preços e a relação dos objetos retidos (art. 703, par. 2, CPC).” (LOUREIRO, 2017, p. 1213).

12 Art. 703. Tomado o penhor legal nos casos previstos em lei, requererá o credor, ato contínuo, a homologação. $\S 1^{\circ} \mathrm{Na}$ petição inicial, instruída com o contrato de locação ou a conta pormenorizada das despesas, a tabela dos preços e a relação dos objetos retidos, o credor pedirá a citação do devedor para pagar ou contestar na audiência preliminar que for designada. $\S 2^{\circ} \mathrm{A}$ homologação do penhor legal poderá ser promovida pela via extrajudicial mediante requerimento, que conterá os requisitos previstos no $\S 1^{\circ}$ deste artigo, do credor a notário de sua livre escolha. $\S 3^{\circ}$ Recebido o requerimento, o notário promoverá a notificação extrajudicial do devedor para, no prazo de 5 (cinco) dias, pagar o débito ou impugnar sua cobrança, alegando por escrito uma das causas previstas no art. 704, hipótese em que o procedimento será encaminhado ao juízo competente para decisão. $\S 4^{\circ}$ Transcorrido o prazo sem manifestação do devedor, o notário formalizará a homologação do penhor legal por escritura pública.

13 "Na ata de exibição de coisas, o tabelião constata a existência material de um ou vários objetos. A mera existência ou inexistência deles num lugar e hora determinados pode ser o objeto da ata. Por exemplo: o lugar em que algo se encontra, o estado ou as circunstâncias em que a coisa é mantida, como as atas de exibição e descrição de coisas, de destruição ou de inutilização de coisas, em especial, documentos.” (RODRIGUES; FERREIRA, 2016).

14 "As atas de presença compreendem situações diversas e imprevisíveis. O tabelião, a pedido do solicitante, na sede do tabelionato ou em diligência externa constata fatos ou circunstâncias, sempre respeitando a sua competência territorial.” (RODRIGUES; FERREIRA, 2016). 
que podem constituir calúnia, injúria ou difamação, ou, ainda, contenham o uso indevido de imagens, de textos extraídos de outras fontes sujeitas ao direito autoral, como livros, filmes, logotipos, marcas, nomes empresariais, músicas e infrações ao direito autoral e intelectual. A caracterização da concorrência desleal também pode ser apurada em decorrência da ata (RODRIGUES; FERREIRA, 2016).

Apesar da diversidade de nomenclaturas, a ata de mera percepção é a ata notarial padrão, aquela que vem à mente quando se fala de ata notarial ${ }^{15}$. Por meio desse tipo de ata, o tabelião constata e registra na ata os acontecimentos captados por meio de seus sentidos.

\subsection{Ata de notoriedade}

Pode ser atestada a notoriedade de um fato por meio de ata notarial; mas qual é a vantagem de se atestar um fato que já é notório? Os fatos não são notórios universalmente. A notoriedade se resume em um determinado lapso espaço-temporal. Pode ser que fora do círculo social imediato do fato a sua notoriedade seja questionada.

Assim, por meio da ata notarial de notoriedade esse conhecimento pode irromper os limites espaço-temporais imediatos. Para comprovar a notoriedade de um fato, o notário poderá realizar diligências para demonstrar de forma inequívoca a sua evidente notoriedade ${ }^{16}$.

Trazendo uma classificação mais detalhada, Velloso (2006) diz que, apesar de poderem ser negados, há muitos fatos que a doutrina aceita como isentos de confirmação: os evidentes, os normais, os notórios, os presumidos pela lei e os negativos. Para o autor, os fatos evidentes são aqueles conhecidos por todos os integrantes de uma determinada sociedade ${ }^{17}$. Por exemplo, é evidente o fato de que é se tem melhor visão das coisas durante o dia do que à noite. Já os fatos notórios:

Son los conecidos y aceptados pacíficamente por muchas personas (no por todas, como el hecho evidente) en una cultura, sociedad o medio determinado. Por ejemplo, el horario de la rueda de negocio sen pleito entre corredores de Bolsa; La ubicación de un hospital en pleito entre médicos que trabajan en él y relacionado con un daño alli producido, etcétera (VELLOSO, 2006, p. 33).

Para um fato ser notório, não é necessário que seja de conhecimento universal, mas que extrapole o círculo de relações particulares, ou seja, faça parte do conhecimento de determinado

15 Já Brandelli (2009, p. 335) aponta a ata de presença como: "São as atas notariais típicas. São aquelas pelas quais o notário narra um fato por ele presenciado, sem influir no desenvolvimento do fato."

16 Segundo Brandelli (2009, p. 336), o regulamento notarial espanhol contém os seguintes preceitos acerca da ata de notoriedade: “Art. 209. [...]. Segundo. El Notario pratictará, para comprobación de la notoriedad pretendida, cuantas pruebas estime necesarias, sean o no propuestas por el requirente, Y deberáh acer requerimientos y notificaciones personales o por edictos cuando el requirente lo pido o él juzge necesario [...]. Tercero. Constrán necesariamente en las actas de notoriedad todas las pruebas practicadas y requerimientos hechos con sus contestaciones; los justificantes de citaciones e llamamientos; la indicación de las reclamaciones presentadas por cualquier interesado, y la reserva de los derechos correspondientes al mismo ante los Tribunales de Justicia."

17 "Son los conocidos por todos los integrantes de una sociedad dada y que, por ende, integran el conociemiento proprio del juez producido por el diário vivir como integrante de aquella" (VELLOSO, 2006, p. 33). 
círculo social em determinado tempo e determinado lugar ${ }^{18}$.

Rodrigues e Ferreira (2016) dão exemplos de aplicação prática da ata de notoriedade:

Algumas pessoas necessitam fazer prova de seu próprio nome, de sua capacidade civil, de seus apelidos ou de outras situações próprias e conhecidas de sua comunidade, mas cuja fé em outros âmbitos depende do ato notarial. Na ata de notoriedade, o tabelião constata $o$ fato mediante verificação de documentos oficiais ou particulares, ou ainda por meio da presença e do testemunho de terceiros visando declarar uma situação notória de interesse do solicitante, podendo ser sobre pessoas e coisas. / É possível atestar alguma situação fática do interessado, como é exemplo a vida. Geralmente solicitada pelo INSS ou algum instituto de previdência ou empresa seguradora, nessa ata o tabelião verifica se a pessoa está viva com a mera presença dela perante ele. / Há casos em que seguradoras, para fazerem o pagamento de benefícios, apólices ou pecúlios, como o DPVAT, seguro obrigatório dos veículos automotores no Brasil, exigem uma ata em que o tabelião ateste a condição de herdeiro legal de um segurado falecido. / O herdeiro comparece perante o tabelião e, mediante a apresentação de documentos oficiais que comprovem o elo sucessório e, se possível, o grau de parentesco do interessado com o de cujus, é possível verificar e atestar a sua situação de herdeiro legal. / Essa ata pode ser complementada também com a declaração de pessoas - mas deve haver prova do encadeamento sucessório -, a parte interessada ou terceiros, de que o de cujus faleceu no estado civil de solteiro, não deixando convivente, filhos, nem testamento. Nesses casos, consideram-se interessados os descendentes, ascendentes, conviventes, parentes colaterais e pessoas que, eventualmente, demonstrem interesse na ata, por exemplo, aquele que é beneficiário de apólice de seguro.

Fica demonstrada a inegável utilidade da ata de notoriedade: o transporte e conservação espaço temporal de um determinado fato tido por notório de um determinado círculo social para outro.

\subsection{Ata de subsanação}

Erros existentes em documentos particulares ou oficiais poderão ser corrigidos pelo tabelião através da ata de subsanação, que é “[...] o instrumento pelo qual o tabelião constata

18 "Pode parecer contraditória a lavratura de ata notarial para constatação de fato notório que, por definição, é conhecido de todos e, consequentemente, não precisa ser demonstrado. Notoriedade de um fato é a qualidade de ser conhecido por todos. / No entanto, o termo 'todos' pode ter amplitudes diversas, ou seja, a notoriedade tem graus diversos. Existem fatos que são conhecidos por qualquer pessoa mediana, onde quer que ela se encontre (fatos vulgarizados). Outros fatos são conhecidos pelas pessoas que, de forma permanente ou duradoura, estão localizados em certo território e a eles relacionados, como cidades, vilas ou distritos (fatos supernotórios). Finalmente, alguns fatos são conhecidos pela generalidade das pessoas que se encontram em uma relação mais próxima ou direta com o evento ou com suas consequências, ou que pertencem ao entorno social ou econômico daquela pessoa a quem o fato afeta (ex: vizinhos, frequentadores do mesmo clube ou igreja, membros da mesma categoria profissional ou empresarial etc.). Estes são denominados fatos simplesmente notórios. / A ata notarial nenhuma utilidade teria, pois nada acrescentaria, no que tange aos fatos vulgarizados: se qualquer pessoa mediana, em qualquer lugar, tem notícia do evento, também o destinatário da prova, obviamente, tem conhecimento do fato. Mas para as demais hipóteses, a ata notarial pode se mostrar útil, como, por exemplo, para a demonstração ou comprovação de estado de posse de filiação; de convivência estável, duradoura e pública entre homem e mulher, como se casados fossem (posse do estado de casado), o estado de solteiro etc.” (LOUREIRO, 2017, p. 1214). 
erros em documentos particulares ou oficiais e os corrige em vista de evidente descompasso entre a situação real e a documental, entre a verdade perceptível e o erro perenizado." (RODRIGUES; FERREIRA, 2016).

A ata de subsanação tem um escopo restrito, não podendo ser utilizada para alterar a vontade das partes externada no documento, mesmo que a vontade tenha sido externalizada com vício. Isso porque o notário não tem o poder de alterar o negócio jurídico: a ata notarial é documento público unilateral do tabelião de notas, podendo ser utilizada para a correção de erros inequívocos, que podem ser constatados de forma objetiva com base em documentação suporte. Nesse sentido, o item 53 do Capítulo XIV da NSCGJ-SP dispõe:

53. Os erros, as inexatidões materiais e as irregularidades, constatáveis documentalmente e desde que não modificada a declaração de vontade das partes nem a substância do negócio jurídico realizado, podem ser corrigidos de ofício ou a requerimento das partes, ou de seus procuradores, mediante ata retificativa lavrada no livro de notas e subscrita apenas pelo tabelião ou por seu substituto legal, a respeito da qual se fará remissão no ato retificado. / 53.1. São considerados erros, inexatidões materiais e irregularidades, exclusivamente: / a) omissões e erros cometidos na transposição de dados constantes dos documentos exibidos para lavratura do ato notarial, desde que arquivados na serventia, em papel, microfilme ou documento eletrônico; / b) erros de cálculo matemático; / c) omissões e erros referentes à descrição e à caracterização de bens individuados no ato notarial; / d) omissões e erros relativos aos dados de qualificação pessoal das partes e das demais pessoas que compareceram ao ato notarial, se provados por documentos oficiais. (SÃO PAULO, 1989, p. 37).

Na sequência, o regulamento administrativo paulista dispõe sobre a impossibilidade de utilização de ata notarial para a correção de escritura pública, sendo necessário nova escritura pública de retificação-ratificação:

54. Os erros, as inexatidões materiais e as irregularidades, quando insuscetíveis de saneamento mediante ata retificativa, podem ser remediados por meio de escritura de retificação-ratificação, que deve ser assinada pelas partes e pelos demais comparecentes do ato rerratificado e subscrita pelo Tabelião de Notas ou pelo substituto legal (SÃO PAULO, 1989, p. 37).

Conjugando os itens 53 e 54, pode-se extrair quando poderá ser realizada a correção da escritura por ata notarial, de forma unilateral pelo tabelião, sem a necessidade de chamar novamente as partes para a confecção de escritura de ratificação-retificação, que exige a anuência de todos as partes que constaram da escritura original. Esclarecedor o parecer 231/2015-E da Corregedoria Geral da Justiça proferido no processo CGJ 73.298/2015, relatado pela Juíza Assessora da Corregedoria Ana Luiza Villa Nova, que aduz:

Em relação à escritura pública, do mesmo modo, considera-se erro material as inexatidões e as irregularidades constatáveis documentalmente e desde que não 
modificada a declaração de vontade das partes nem a substância do negócio jurídico, os quais podem ser corrigidos de ofício ou a requerimento das partes, mediante anotação à margem do ato notarial ou, não havendo espaço, por meio de ata retificativa lavrada no livro de notas e subscrita apenas pelo tabelião, a respeito da qual se fará remissão no ato retificativo, nos termos do art. 53 do Capítulo XIV das Normas de Serviço da Corregedoria Geral de Justiça. O subitem 53.1 descreve em suas quatro alíneas quais são os erros, inexatidões materiais e irregularidades passíveis de correção de ofício ou a requerimento das partes, e, na alínea "d", prevê hipótese que se enquadra no caso vertente - "omissões e erros relativos aos dados de qualificação pessoal das partes e das demais pessoas que comparecem ao ato notarial, se provados por documentos oficiais (SÃO PAULO, 2015).

A ata de subsanação permite, de forma rápida, precisa e segura a correção de erros constatáveis materialmente pelo notário, evitando que o usuário tenha que se deslocar novamente para a feitura de uma nova escritura pública de retificação-ratificação, contribuindo para a redução do custo Brasil, e evitando potenciais conflitos que poderiam surgir em decorrência de eventual desacordo superveniente entre as partes.

Assim, a ata de subsanação é um instrumento que contribui com a desburocratização ao permitir que o próprio tabelião de notas, em certas hipóteses restritas, saneie o ato, sem a necessidade de intervenientes.

\subsection{Carta de sentença notarial}

As cartas de sentença notariais foram inseridas nas Normas de Serviço da Corregedoria Geral da Justiça do Estado de São Paulo por meio do Provimento CG no 31/2013 (SÃO PAULO, 2013). Tal instrumento não existe em todos os Estados, dependendo de regulamentação pelo respectivo tribunal de justiça.

Nos "considerandos" do provimento paulista foi destacada a fé pública do tabelião, "[...] que lhes permite constatar e atestar fatos, bem como certificar a correspondência entre cópias e os respectivos autos judiciais originais"; “[...] que existe estreita afinidade entre as atividades judiciais e extrajudiciais, com ampla possibilidade de conjugação de tarefas, em benefício do serviço público"; "[...] que deve ser permanente a busca pela celeridade e eficiência nos serviços judiciários" (SÃO PAULO, 2013).

Assim, o Capítulo XIV da NSCGJ-SP, que regulam o serviço do tabelionato de notas, passou a contar com a Seção XII - Das cartas de sentença notariais (SÃO PAULO, 1989, p. 62). O fundamento da carta de sentença notarial reside na fé pública e no poder autenticatório do tabelião. E esses poderes são os mesmos que dão base para a lavratura de atas notariais. Para Loureiro, a

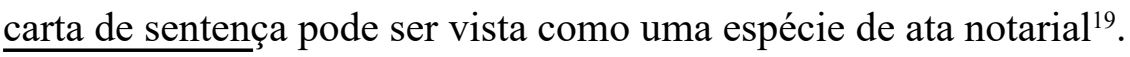

19 “A denominada carta de sentença notarial, ademais de possuir, nosso entender, a natureza de ata notarial de protocolização, tal como amplamente reconhecido no direito comparado, também pode ser classificada como uma atividade de jurisdição voluntária (administração pública de interesses privados) que é transferida pela autoridade judicial ao notário, o qual fica incumbido de conservar nos seus arquivos o expediente judicial, neles inserido por 
Outro fundamento também que pode ser utilizado para justificar a carta de sentença notarial é o disposto no inciso III do art. 425 do $\mathrm{CPC} / 15^{20}$. As reproduções das peças dos autos são cópias de documentos públicos, e a reprodução por notário atribui a autenticidade em função da fé pública investida pelo Estado a esse profissional do direito.

A expedição da carta de sentença não é um ato jurisdicional, mas, sim, administrativo. A sentença envolve o poder jurisdicional em ação, sendo a manifestação do magistrado uma exteriorização de parcela do poder soberano do Estado. $O$ instrumento que materializa a reprodução de tal expressão de vontade, todavia, não é um ato jurisdicional em sentido estrito, podendo ser repassado tranquilamente para oficiais que estão sob o regime do direito administrativo.

Para o Poder Judiciário, essa iniciativa é bem-vinda pois contribui para descongestionar o sistema, transferindo carga de serviço para a estrutura extrajudicial. Assim, os servidores que seriam encarregados dessa tarefa administrativa podem se dedicar melhor à atividade fim do Poder Judiciário: resolver conflitos de interesses em que o exercício da jurisdição seja indispensável e intransferível. Ainda, a carta de sentença notarial é mais uma alternativa que se coloca à disposição do usuário, que pode, em prazo curto, obter a materialização da ordem judicial, vantagem considerável principalmente em relação àquelas varas que sofrem com acúmulo de serviço e falta de servidores e infraestrutura.

Para o tabelião de notas, a ata notarial é mais um ato integrante da sua carteira de serviços, aumentando o seu leque de atuação, sendo, portanto, interessante. Além disso, é o reconhecimento de sua capacidade como um auxiliar para dar impulso aos atos necessários para a efetivação da jurisdição.

A ata notarial é um instituto de grande potencial, mas ainda de pouca utilização prática. Espera-se, com esse estudo, aumentar a divulgação e reflexão acerca desse instituto, que tem o potencial de contribuir para um melhor acesso à justiça no Brasil.

\section{CONCLUSÃO}

O presente artigo discorreu sobre a ata notarial, instrumento público, destinada à préconstituição de prova, mediante a qual o tabelião de notas, a requerimento da parte, relata fatos percebidos de forma seletiva sem emissão de juízo de valor, dando o seu testemunho, que é recoberto pela fé pública outorgada pelo Estado. Após a análise da estrutura da ata notarial, foram minudenciados quatro tipos de ata notarial: ata de mera percepção, ata de notoriedade, ata de subsanação e carta de sentença notarial.

A ata de mera percepção é a ata notarial clássica, e seu uso tem aumentado para documentar fatos que de outra forma seriam de difícil prova, como determinada mensagem postada em rede social na internet.

força da ata notarial de protocolização, e de emitir traslados e certidões desde documento matriz. Desta forma, retirase do Judiciário uma função administrativa, que contribui para emperrar os mecanismos da máquina judicial, para que se volte à sua verdadeira função: a denominada jurisdição contenciosa." (LOUREIRO, 2017, p. 1218).

20 Art. 425. Fazem a mesma prova que os originais: [...] III - as reproduções dos documentos públicos, desde que autenticadas por oficial público ou conferidas em cartório com os respectivos originais; [...]. 
A ata de notoriedade consegue realizar o transporte espaço-temporal de um determinado círculo social de um fato considerado notório para outros contextos, nos quais a notoriedade poderia ser contestada.

A ata de subsanação contribui para a correção de determinados erros objetivos quando da lavratura de uma escritura pública, por ato unilateral do notário, de forma a ser desnecessária o comparecimento ou anuência dos partícipes do ato original, que poderiam entrar em desacordo posterior, evitando a intervenção judicial.

A carta de sentença notarial é uma novidade introduzida no código de normas paulista e que ainda não foi difundida pelo Brasil. Por meio dela, pode-se deslocar parte do serviço que consome recursos do Poder Judiciário, como escreventes e estagiários, para a estrutura extrajudicial, sem perda de qualidade, visto que os titulares das serventias extrajudiciais são dotados de fé pública.

Com a transferência, os serventuários do juízo ficam liberados para novas tarefas de apoio ao magistrado, como a realização de minutas, tentativa de conciliação e mediação entre as partes, organização dos processos da vara e outras atividades essenciais ao bom desempenho da função jurisdicional.

O sistema notarial e registral contribui para a produção e distribuição da justiça preponderantemente por meio da prevenção de litígios, trazendo a lume outro enfoque: o direito como forma de prevenir o conflito, e não como um conjunto de técnicas voltadas a solucionar a lide.

A ata notarial é um instituto de grande potencial, mas ainda de pouca utilização prática. Espera-se, com esse artigo, aumentar a divulgação e reflexão acerca instituto, que tem o potencial de contribuir para um melhor acesso à justiça no Brasil.

\section{REFERÊNCIAS}

BRANDELLI, Leonardo. Teoria geral do direito notarial. 3. ed. São Paulo: Saraiva, 2009.

BRASIL. Lei n⿳ 10.406, de 10 de janeiro de 2002. Institui o Código Civil. Brasília: Presidência da República, 2002. Disponível em: http://www.planalto.gov.br/ccivil_03/LEIS/2002/L10406. htm. Acesso em: 8 mar. 2018.

BRASIL. Lei no 13.105, de 16 de março de 2015. Código de Processo Civil. Brasília: Presidência da República, 2015. Disponível em: http://www.planalto.gov.br/ccivil_03/_Ato20152018/2015/Lei/L13105.htm. Acesso em: 7 mar. 2018.

BRASIL. Lei no 5.869, de 11 de janeiro de 1973. Institui o Código de Processo Civil. Brasília: Presidência da República, 1973. Disponível em: http://www.planalto.gov.br/ccivil_03/leis/ L5869impressao.htm. Acesso em: 6 mar. 2018.

BRASIL. Lei no 8.935, de 18 de novembro de 1994. Regulamenta o art. 236 da Constituição Federal, dispondo sobre serviços notariais e de registro. (Lei dos cartórios). Brasília: Presidência da República, 1994. Disponível em: http://www.planalto.gov.br/ccivil_03/LEIS/L8935.htm. Acesso em: 5 mar. 2018. 
CENEVIVA, Walter. Lei dos notários e registradores comentada: lei n. 8.935/94. 8. ed. São Paulo: Saraiva, 2010.

DELLEPIANE, Antonio. Nova teoria da prova. Campinas: Editora Minelli, 2004.

LOUREIRO, Luiz Guilherme. Registros públicos: teoria e prática. 8. ed. Salvador: Juspodivm, 2017.

MINAS GERAIS. Tribunal de Justiça. Corregedoria-Geral da Justiça. Provimento $\mathbf{n}^{\mathbf{0}} \mathbf{2 6 0}$ / CGJ/2013. Codifica os atos normativos da Corregedoria-Geral de Justiça do Estado de Minas Gerais relativos aos serviços notariais e de registro. Belo Horizonte: Corregedoria-Geral da Justiça, 2013. Disponível em: https://www8.tjmg.jus.br/institucional/at/pdf/cpr02602013.pdf. Acesso em: 1 mar. 2018.

NEVES, Daniel Amorim Assumpção. Manual de direito processual civil. 9. ed. Salvador: Juspodium, 2017.

PEDROSO, Regina; LAMANAUSKS, Milton. Direito notarial e registral. Rio de Janeiro: Elsevier: Campus, 2013.

RODRIGUES, Felipe Leonardo; FERREIRA, Paulo Roberto Gaiger. Tabelionato de notas II: atos notariais em espécie. São Paulo: Saraiva, 2016. (Coleção Cartórios).

SÃO PAULO (Estado). Corregedoria Geral da Justiça. Normas de serviço: cartórios extrajudiciais. S]ao Paulo: Corregedoria Geral da Justiça, 1989. Tomo II.

SÃO PAUlO (Estado). Tribunal de Justiça. Corregedoria Geral da Justiça. Processo CGJ 73.298/2015. São Paulo: Corregedoria Geral da Justiça, 2015. Disponível em: https://www. portaldori.com.br/2016/02/04/cgjsp-tabeliao-de-notas-pedido-de-retificacao-de-escritura-publicaerro-de-qualificacao-que-configura-erro-material-hipotese-que-se-enquadra-no-item-53-esubitem-53-1/. Acesso em: 3 mar. 2018.

SÃO PAULO (Estado). Tribunal de Justiça. Corregedoria Geral da Justiça. Provimento CG no 31/13. Regulamenta a formação extrajudicial de cartas de sentença, a partir dos autos judiciais originais, ou do processo judicial eletrônico, pelos tabeliães de notas. São Paulo: Corregedoria Geral da Justiça, 2013. Disponível em: https://www.migalhas.com.br/arquivos/2013/11/ art20131107-10.pdf. Acesso em: 2 mar. 2018.

VELLOSO, Adolfo Alvarado. La prueba judicial: reflexiones críticas sobre la confirmación procesal. Valencia: Tirant lo Blanch, 2006.

Como citar: SILVA, Nelson Finotti; KIRIHATA, Renan. Ata Notarial. Scientia Iuris, Londrina, v. 23, n. 1, p. 10-24, mar. 2019. DOI: 10.5433/2178-8189.2019v23n1p10. ISSN: 2178-8189.

Recebido em: 04/06/2017.

Aprovado em: 03/10/2018. 